\title{
Characterization of a cyclic olefin polymer microcentrifuge tube
}

\author{
Lloyd Waxman, Rachel L. Erwin ${ }^{\dagger}$, and Vinod D. Vilivalam \\ ${ }^{1}$ West Pharmaceutical Services, Exton, PA
}

†Present address: Regeneron Pharmaceuticals, Inc., Tarrytown, NY

BioTechniques 62:223-228 (May 2017) doi 10.2144/000114546

Keywords: microcentrifuge tube; cyclic olefin polymer; polypropylene; cyclic olefin copolymer

Here, we describe the properties of a prototype microcentrifuge tube made from the plastic cyclic olefin polymer (COP). This material has been used in the manufacture of primary containers including syringes and vials for the storage, shipment, and delivery of biotherapeutics, vaccines, and cell therapy products. Its low level of extractable substances and metals along with its glass-like clarity make COP an attractive material for the fabrication of microcentrifuge tubes and other consumable laboratory plasticware where contamination is an important consideration, such as in the storage and analysis of labile proteins, nucleic acids, and metabolites. We compare the performance of microcentrifuge tubes made of COP with that of several brands made of polypropylene (PP), the plastic most widely used in the manufacture of microcentrifuge tubes. Our results show COP microcentrifuge tubes perform as well as tubes made of PP, with reduced levels of compounds capable of leaching into solvents typically used in the laboratory.

Due to their chemical inertness, break resistance, and moldability, plastic resins are widely used for the manufacture of disposable items for analytical and biochemical laboratories, including test tubes, tubing, vials for storage and sampling, and centrifuge tubes. The same properties and lower cost have also made the use of plastics more attractive than glass or metal for a wide array of other applications. Microcentrifuge tubes made of polypropylene (PP) and capable of holding 1.5-2.0 mL of solution have long been used for the storage and processing of biological samples, including proteins/peptides, nucleic acids, and low-molecular-weight biomolecules. However, like most consumables manufactured from plastic, these tubes may contain numerous chemical additives, including antioxidants, mold release agents, biocides, and UV-light stabilizers. Other low-molecular-weight materials, including unreacted monomers and polymer degradation products, may also be present.

A study by Lewis et al. (1) provided clear evidence that leaching of these substances could potentially interfere with the determination of nucleic acid and protein concentration by UV spectrometry, particularly at a wavelength of $260 \mathrm{~nm}$. The magnitude of leaching was greatly dependent on the nature of the solvent and also the time and temperature of incubation, but it appeared to be ubiquitous among the different brands of microcentrifuge tubes that were tested. Additives present in laboratory plasticware, including microcentrifuge tubes, have also been reported to inhibit enzymatic activity and ligand binding assays (2). To mitigate this problem, some manufacturers have begun to offer PP-based tubes that contain fewer additives. Another approach would be to identify alternative plastics that retain the positive attributes found in existing tubes, including low chemical reactivity, high temperature stability, and resistance to oxidation, but which contain fewer leachable substances, particularly those that absorb light in the UV range.

Compared with the traditional plastic resins, the development and application of cyclic olefin polymers (COPs) is relatively new. COPs are prepared by addition polymerization of monocyclic olefins, cyclobutane or cyclopentane, or bicyclic olefins such as norbornene (3). Mitsui and Hoechst used single-site metallocene catalysis to polymerize cyclic olefins, leading to the development of the cyclic olefin copolymer (COC) Topas by Ticona $(3,4)$. Another commercially viable route is through a two-step process based on the ring-opening metathesis polymerization of dicyclopentadiene followed by complete hydrogenation of the double bonds to form COPs (5). Zeon Corporation has developed a series of COPs with different physical properties using this method. A similar process resulted in another COP

\section{METHOD SUMMARY}

Microcentrifuge tubes made of cyclic olefin polymer (COP) are compared with standard polypropylene (PP) tubes. COP tubes have a glass-like clarity and reduced amounts of extractable substances capable of interfering with enzyme- and cell-based assays. COP tube performance is comparable to polypropylene tubes with respect to centrifugation at high speed, solvent and $\mathrm{pH}$ resistance, break-resistance when frozen, and autoclavability with steam. 
plastic, called Daikyo Crystal Zenith (CZ) (available from Daikyo Seiko, Ltd.), which is currently used in the manufacture of drug container systems for the pharmaceutical industry (5) and for stem-cell research (6). This material was used to produce the microcentrifuge tubes described in this study.

Both COP and COC possess many desirable characteristics, such as glass-like clarity and good melt flow properties, that readily lend themselves to molding and thermal forming. Both polymers exhibit a high impact and break resistance, and they form an excellent moisture barrier (3). COP is extremely low in extractables and has no detectable ion extractables (7). In addition, both materials possess good chemical resistance to acids, bases, surfactants, and alcohols, and they can be sterilized using autoclaves, ethylene oxide, and radiation (5). The unique properties of these materials have been made them desirable for the fabrication of multi-well plates (8) and as a replacement for glass in lab-on-a chip applications (9). Here, we describe the properties of $1.5 \mathrm{~mL}$ microcentrifuge tubes made from $\mathrm{CZ}$ polymer and compare these tubes with several brands made from PP.

\section{Materials and methods}

\section{Reagents and chemicals}

Angiotensin I was purchased from Sigma-Aldrich (St. Louis, MO), and fluorescein-labeled BSA was purchased from Rockland Immunochemicals (Limerick, PA). TRI Reagent for use in a single-step isolation of RNA and DNA from cells and tissues and GC-grade solvents used in this study were purchased from Sigma-Aldrich. Laboratory-purified water, the equivalent of Milli-Q water, was used to prepare solvents for HPLC analysis and extractables studies.

\section{Microcentrifuge tubes}

The different brands of tubes used in this study were obtained from VWR (Radnor, PA) except for tubes made from CZ, which were provided by Daikyo Seiko, Ltd. (Tokyo, Japan).

Reverse phase-HPLC analysis of peptide recovery and leachables from microcentrifuge tubes

A Waters Model 2695 HPLC (Waters Corporation, Milford, MA) equipped with autosampler and photo diode array detector was used to analyze peptides and leachable materials. Samples were chromatographed on a Jupiter $2.0 \times 150 \mathrm{~mm}$ C18 column (Phenomenex, Inc., Torrance, CA) maintained at $26^{\circ} \mathrm{C}$. The column was equilibrated in $0.1 \%$ trifluoroacetic acid in water and developed with a linear gradient of $0.085 \%$ trifluoroacetic acid in acetonitrile over 20 min. Material eluting from the column was monitored at 200, 220, 240, 260, and $280 \mathrm{~nm}$

\section{Adsorption studies}

A $1 \mathrm{mg} / \mathrm{mL}$ solution of angiotensin I was prepared by dissolving $1 \mathrm{mg}$ of peptide powder in $1.0 \mathrm{~mL}$ water by weight using a glass Pasteur pipette. A $1.0 \mathrm{~mL}$ aliquot of this solution was then diluted with $99 \mathrm{~mL}$ water to give a $10 \mu \mathrm{g} / \mathrm{mL}$ solution of angiotensin I. One milliliter of the dilution was transferred into each of three tubes of each brand of microcentrifuge tube using a glass Pasteur pipette. The tubes were capped and stored at $5^{\circ} \mathrm{C}$ for $24 \mathrm{~h}$. Samples were poured into glass HPLC vials for analysis, and a fresh 10 $\mu \mathrm{g} / \mathrm{mL}$ solution was prepared to serve as the control. The peptide

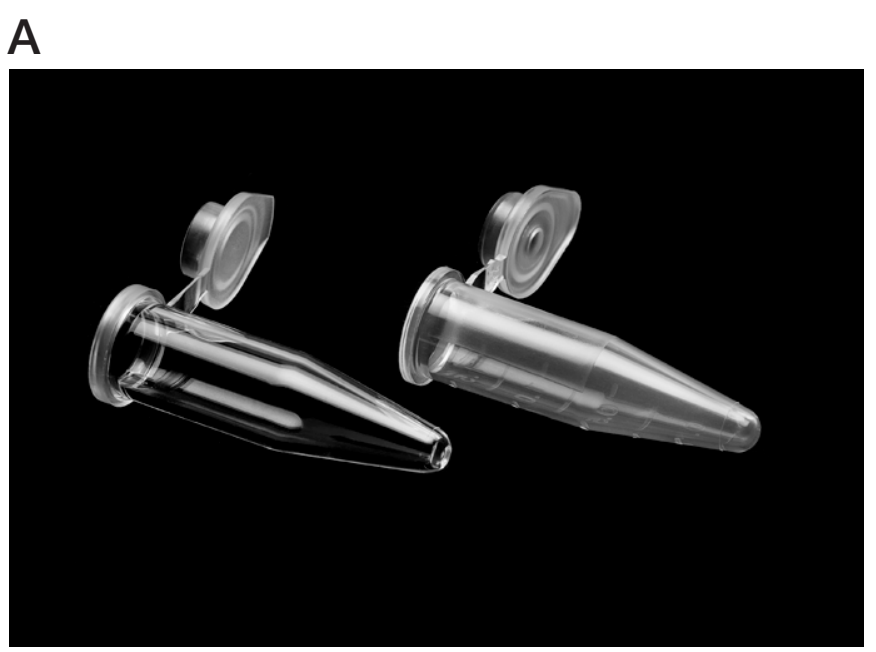

\section{B}

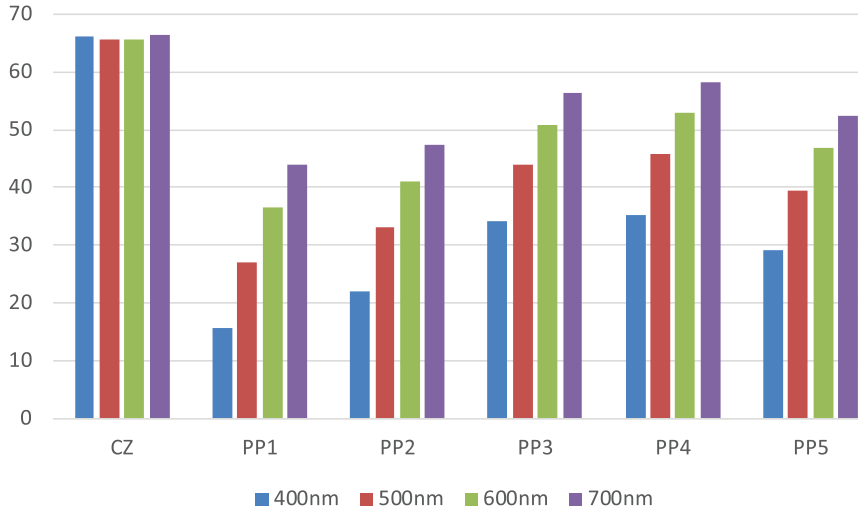

Figure 1. Optical properties of the Daikyo Crystal Zenith (CZ) microcentrifuge tube. (A) Microcentrifuge tubes made of the cyclic olefin polymer (COP) CZ (left) and polypropylene (PP) (right). (B) Comparison of percent light transmittance through microcentrifuge tubes made of $C Z$ and $P P$.

was monitored at $220 \mathrm{~nm}$ and $280 \mathrm{~nm}$, and there was excellent agreement at both wavelengths. The area under the peptide peak was proportional to the amount injected. The peak area of the control did not change during the course of the analysis.

A $1 \mathrm{mg} / \mathrm{mL}$ solution of fluorescein-labeled BSA was reconstituted by addition of $1.0 \mathrm{~mL}$ water to a vial containing $1 \mathrm{mg}$ of lyophilized protein. Twenty-five microliters of this solution was diluted with $25 \mathrm{~mL}$ water in a borosilicate glass vial to give a final concentration of $1 \mu \mathrm{g} / \mathrm{mL}$. One milliliter of the diluted solution was transferred using a glass Pasteur pipette into each of three tubes of each brand of microcentrifuge tube. The tubes were capped and stored at $5^{\circ} \mathrm{C}$ for $24 \mathrm{~h}$. The content of each tube was poured directly into disposable $1.5 \mathrm{~mL}$ polystyrene fluorometer cuvettes (International Crystal Laboratories, Garfield, NJ). A fresh $1 \mu \mathrm{g} / \mathrm{mL}$ solution was also prepared to serve as the control since preliminary experiments indicated that some of the original stock solution had adsorbed to the glass vial in which it was stored.

Fluorescence was measured on a Spex Fluoro-Max 2 fluorometer (Horiba Scientific, Edison, NJ). Excitation was at 494 $\mathrm{nm}$, and the emission wavelength was set at $521 \mathrm{~nm}$.

In both types of adsorption experiment, the percent of peptide or protein adsorbed was calculated by taking the difference between the signal due to the control minus the signal due to the sample divided by the control signal and multiplying the result by 100 . 


\section{Leachables studies}

One milliliter of laboratory purified water or a solution of $10 \mathrm{mM}$ Tris/1 mM EDTA, pH 8.0 (TE buffer) was transferred to each of 3 tubes of each brand of microcentrifuge tube. A glass Pasteur pipette was used to eliminate the possibility of contamination by leachables from plastic pipettes. Samples containing water were capped and heated at $95^{\circ} \mathrm{C}$ for $30 \mathrm{~min}$, and those containing TE buffer were capped and incubated in an oven for 3 days at $57^{\circ} \mathrm{C}$. Samples were scanned in quartz cuvettes from $360 \mathrm{~nm}$ to 200 $\mathrm{nm}$ and blanked against the appropriate control solution. A PerkinElmer Lambda 35 spectrometer (PerkinElmer, Waltham, MA) was used for all absorbance measurements. The same samples were also analyzed by reverse phase-HPLC as described above.

Microcentrifuge tubes were filled with $1 \mathrm{~mL}$ methanol, dimethyl sulfoxide (DMSO), or 10\% (w/v) trichloroacetic acid and stored for 7 days at room temperature. The solutions were analyzed directly by reverse phase-HPLC with the exception of the methanol extracts, which were allowed to evaporate and were then redissolved in water before injection.

The microcentrifuge tubes filled with DMSO or methanol and stored for 7 days were also examined for semivolatile organic compounds by GC/MS using direct injection. Samples were analyzed on a Hewlett Packard Model 7890 gas chromatograph (Agilent Technologies, Santa Clara, CA) equipped with a Restek Rtx-5MS fused silica column (Restek, Bellefonte, PA) and a Hewlett Packard Model 5077 MS detector; the carrier gas was helium. Significant peaks were defined as peaks that are detected in samples with a signal-to-noise ratio of 10 , which is equivalent to a reporting threshold of $0.1 \mu \mathrm{g} / \mathrm{tube}$, but that are not detected in the extraction blank.

\section{Transmittance measurements}

Transmittance of light at different visible wavelengths was compared by placing the inverted microcentrifuge tube into the sample side of the cuvette holder; the reference side was left empty. Light transmittance was measured at a series of wavelengths from 400-700 nm.

\section{Results and discussion}

\section{CZ microcentrifuge tube transparency}

Figure $1 \mathrm{~A}$ shows a photograph of the $\mathrm{CZ}$ microcentrifuge tube used in this study. A typical microcentrifuge tube made of PP is shown for comparison. Unlike PP, CZ has limited flexibility, which prevents the use of $\mathrm{CZ}$ to form the arm that tethers the cap to the tube. Consequently, the prototype shown is constructed of two pieces: the tube, which is made of $C Z$, and a separate cap made of PP. The clarity of $\mathrm{CZ}$ permits greater light transmittance at visible wavelengths than the standard tube made of PP, which is translucent (Figure 1B). This property can be advantageous when visually inspecting a solution for the presence of low levels of visible particles or small amounts of pelleted material after centrifugation. A visual comparison of tubes filled with $1 \mathrm{~mL}$ of water demonstrated that the CZ tube enables users to easily determine that the solution is free of particulates, whereas it is more difficult to draw this conclusion with a tube made of PP.

\section{Comparisons of performance properties}

Centrifugation: Tubes filled with water were centrifuged at 20,000 x $g$ for 1 hour at $25^{\circ} \mathrm{C}$. Neither tubes made of PP nor the ones made of $\mathrm{CZ}$ showed any visible evidence of cracking or deformation. Tubes were not tested at higher centrifugal forces due to performance limitations of the centrifuge.

Sterilization: Empty tubes that were autoclaved for $1 \mathrm{~h}$ at $121^{\circ} \mathrm{C}$ showed no evidence of cracks. The autoclaved tubes were then filled with $1 \mathrm{~mL}$ water and centrifuged for 1 hour at 20,000 $\times \mathrm{g}$. The tubes showed no cracks or deformations.

Freeze-thaw: Solution samples are routinely stored frozen in microcentrifuge tubes at $-20^{\circ} \mathrm{C}$ and $-80^{\circ} \mathrm{C}$. Tubes filled with $1 \mathrm{~mL}$ water that were subjected to multiple freeze-thaw cycles at either temperature did not crack or leak.

Chemical stability: CZ microcentrifuge tubes are resistant to most solvents typically used in the biochemistry laboratory, including aqueous solutions of both high and low pH, dimethyl sulfoxide, dimethyl formamide, acetonitrile, alcohols (including isopropanol and ethanol), fatty acids, vegetable oil, and surfactants such as sodium dodecyl sulfate and Polysorbates 20 and 80 . Unlike tubes made of PP, CZ begins to soften after several hours when exposed to chloroform. However, when small amounts of chloroform were used to isolate RNA from rat liver according to a well-established procedure $(10,11)$, tubes made of $\mathrm{CZ}$ performed as well as ones made of PP. In addition, the transparency of the $\mathrm{CZ}$ tubes made it easier to see the three phases after centrifugation of the tissue extract.

\section{Adsorption of peptides and proteins}

The loss of valuable proteins and peptides due to adsorption to the walls of microcentrifuge tubes is a common problem, particularly for low concentration samples. We compared adsorption of fluorescein-labeled BSA (1 $\mu \mathrm{g} / \mathrm{mL})$ and the 12-amino-acid peptide

\section{BEAD RUPTOR ELITE Bead Mill Homogenizer}

\section{Because Results Matter}
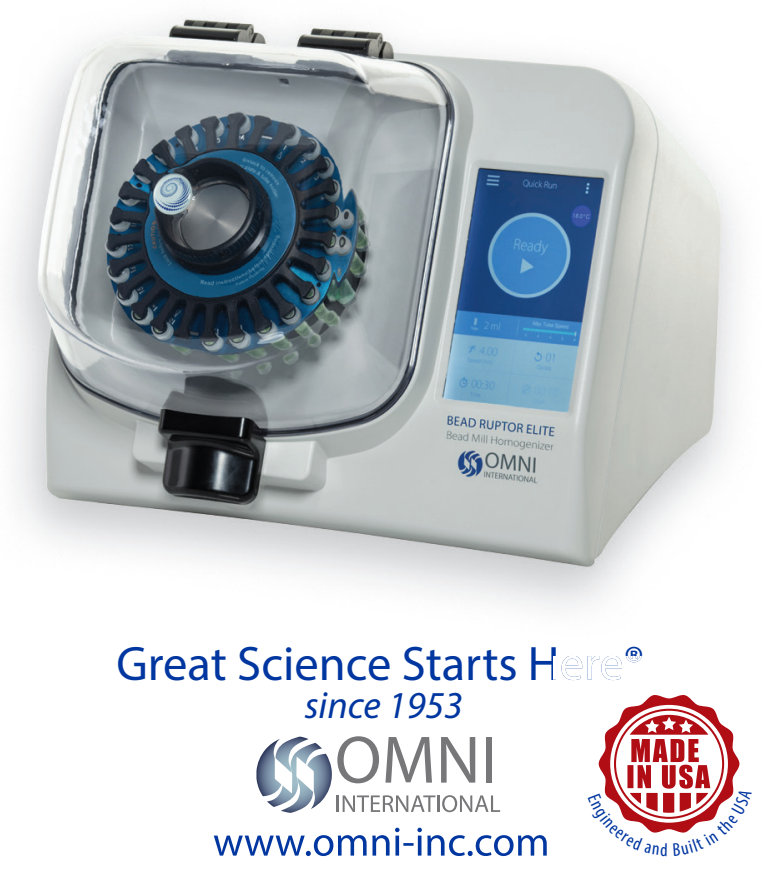
angiotensin I $(10 \mu \mathrm{g} / \mathrm{mL})$ to different brands of tubes made of PP and to the $\mathrm{CZ}$ tube. After storage for $24 \mathrm{~h}$ at $2^{\circ} \mathrm{C}-8^{\circ} \mathrm{C}$, all of the tubes adsorbed comparable amounts of BSA: $25 \%-30 \%$, corresponding to $250-300 \mathrm{ng} /$ tube. Similarly, the fraction of angiotensin I adsorbed to the different brands of tubes made of PP and to the tube made of $C Z$ was in the same range $(15 \%-20 \%)$, corresponding to $1.5-2.0$ $\mu \mathrm{g}$ of peptide. Thus, the adsorption of peptides and proteins to the tube made of $\mathrm{CZ}$ is comparable to the tubes made of PP.

Leachables from CZ microcentrifuge tubes

Lewis et al. (1) provided strong evidence that most brands of PP tubes contain leachable substances capable of absorbing light in the UV range. This could result in inaccuracies in the determination of the concentration and purity of nucleic acids or proteins in solution, especially when present at low concentrations. In addition, the use of tubes with high levels of leachable materials could cause difficulties in the interpretation of LC, LC/MS, GC, and GC/MS chromatograms in leachables/extractables studies. Such studies of primary containers for drug products, including vials and prefillable syringes, are required by the United States Food and Drug Administration (FDA). Therefore, we used UV spectroscopy and reverse phase-HPLC to compare leachables profiles of the microcentrifuge tube made of $\mathrm{CZ}$ with ones made of PP using solvents typically employed in the manipulation and analysis of biomolecules and metabolites. Researchers frequently heat samples to denature proteins and DNA as well as to inactivate enzymes. Microcentrifuge tubes filled with $1 \mathrm{~mL}$ water were heated to $95^{\circ} \mathrm{C}$ for $30 \mathrm{~min}$, and the solutions were analyzed by UV spectroscopy. Figure 2A compares the spectra from water heated in CZ tubes with five brands of tubes made of PP. Extracts prepared using tubes made of $\mathrm{CZ}$ had the lowest absorbance over the range of $200-280 \mathrm{~nm}$. The same result was obtained when aqueous solutions of $0.1 \%$ SDS, an ionic detergent frequently used to solubilize and denature proteins, was heated to $95^{\circ} \mathrm{C}$ for $30 \mathrm{~min}$ (data not shown). Storage of water in the $\mathrm{CZ}$ microcentrifuge tube at room temperature for $24 \mathrm{~h}$ released some $\mathrm{UV}$-absorbing material, but relatively less than the amounts released from tubes made of PP (data not shown). TE, a buffer commonly used for molecular biology applications (12), was stored in tubes held at $57^{\circ} \mathrm{C}$ for 3 days. Although the amount of material leached from tubes held at $57^{\circ} \mathrm{C}$ was lower than from the tubes held at $95^{\circ} \mathrm{C}$, the absorbance over the same range was lowest in samples stored in CZ tubes (Figure 2, B and C). The absorbance at $260 \mathrm{~nm}$ due to leachable substances could potentially result in an overestimation of $>3 \mu \mathrm{g} /$ $\mathrm{mL}$ of the concentration of a solution of DNA (Table 1).

To assess the diversity of molecules present in both the water and TE extracts, $100 \mu \mathrm{l}$ of each sample was analyzed by reverse phaseHPLC on a C18 column (Figure 3). In accordance with the UV results, the HPLC profile of solutions stored in CZ tubes shows fewer species and the total integrated area under the peaks is much smaller. Several other solvents were also investigated, including methanol, $10 \%(\mathrm{w} / \mathrm{v})$ trichloroacetic acid (TCA), 100\% DMSO, and 10\% (v/v) DMSO. Analyses were carried out using HPLC since these solvents absorb light in the UV range. In all cases, less material was leached into solution from tubes made of CZ than PP. Semivolatile organic compounds were also examined by GC/MS when the tubes were extracted with methanol or DMSO. Among the compounds positively identified in these extracts were methyl palmitate, methyl stearate, hexadecanamide, octadecenamide and octadecanamide. Several of these compounds are fatty acid amides that are typically used

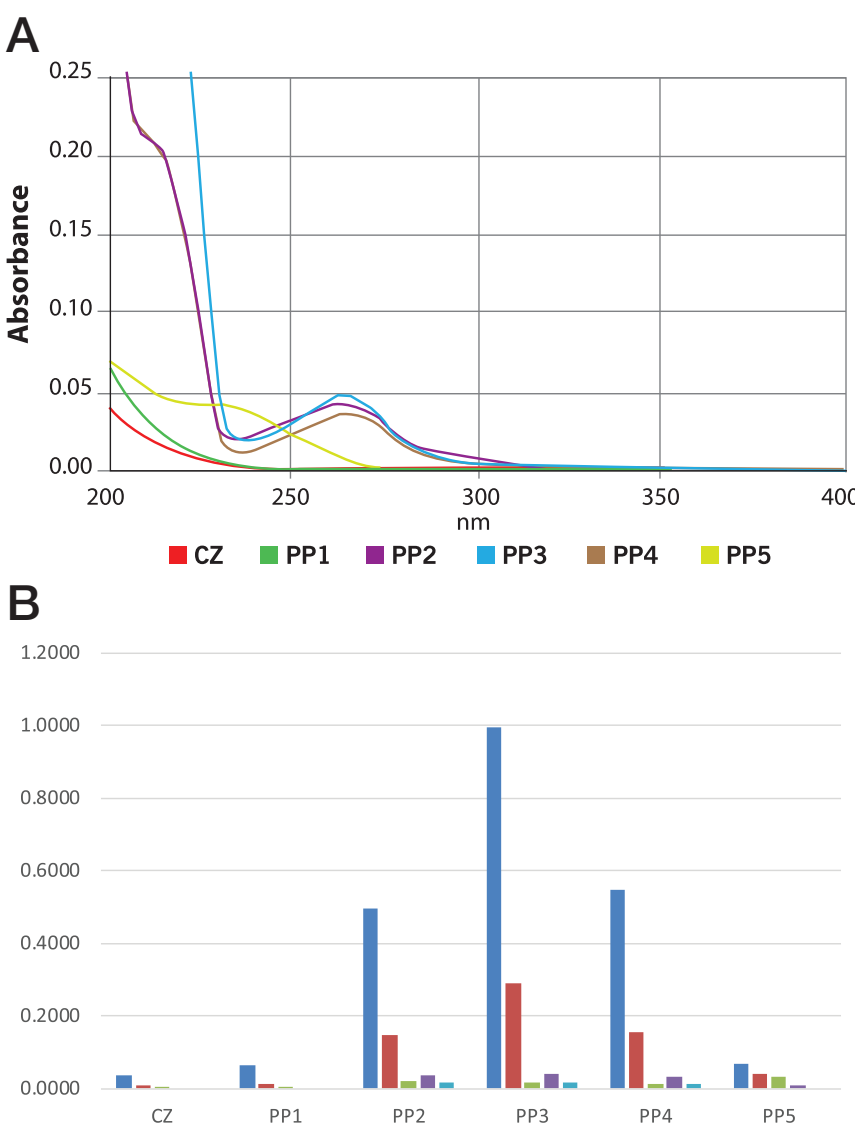

C

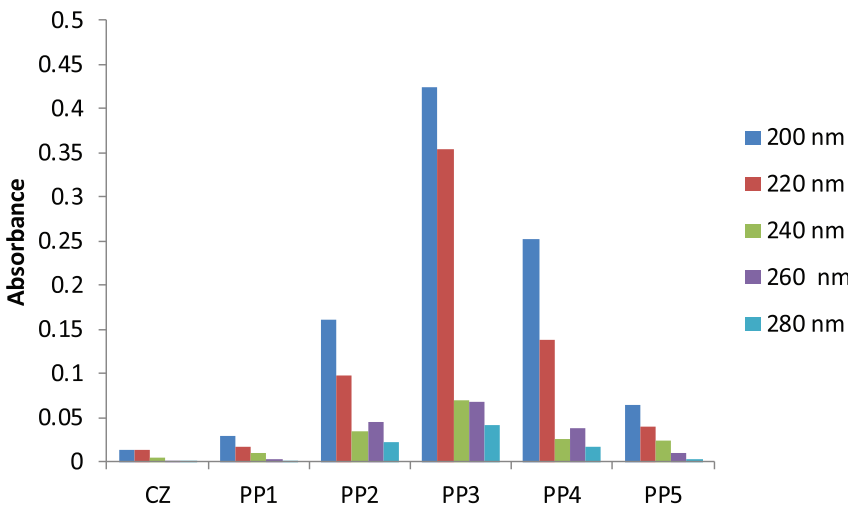

Figure 2. Comparison of absorbance due to leachables from microcentrifuge tubes. (A) UV spectra of leachables from various microcentrifuge tubes containing water and heated to $95^{\circ} \mathrm{C}$. (B) UV absorbances from tubes held at $95^{\circ} \mathrm{C}$ for 30 min filled with water and (C) tubes held at $57^{\circ} \mathrm{C}$ for 3 days filled with TE buffer.

Table 1. Overestimation of DNA concentration due to UV-absorbing materials leached from microcentrifuge tubes.

\begin{tabular}{|c|c|c|}
\hline & \multicolumn{2}{|c|}{ Hg DNA overestimated } \\
\hline & $95^{\circ} \mathrm{C} / 30 \mathrm{~min}$ & $57^{\circ} \mathrm{C} / 3$ days \\
\hline $\mathrm{CZ}$ & 0.00 & 0.06 \\
\hline PP1 & 0.00 & 0.18 \\
\hline PP2 & 1.94 & 2.23 \\
\hline PP3 & 2.15 & 3.36 \\
\hline PP4 & 1.66 & 1.88 \\
\hline PP5 & 0.51 & 0.48 \\
\hline
\end{tabular}

This calculation is based on an average extinction coefficient for doublestranded DNA of $0.02(\mu \mathrm{g} / \mathrm{mL})^{-1} \mathrm{~cm}^{-1}$ at $260 \mathrm{~nm}(12)$. 

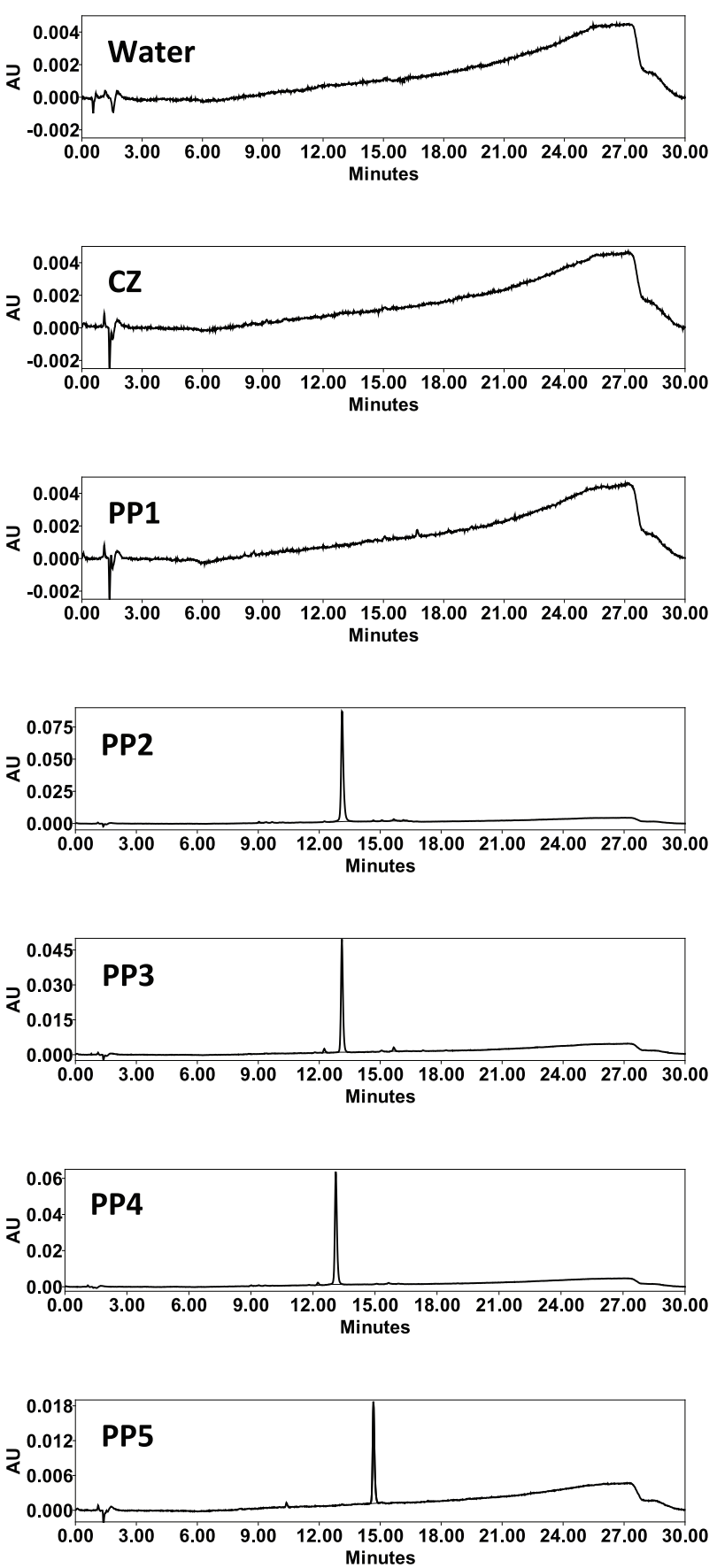

Figure 3. Reverse phase HPLC of water extracts from microcentrifuge tubes held at $95^{\circ} \mathrm{C} / 30 \mathrm{~min}$.

Table 2. GC/MS analysis of microcentrifuge tubes extracted with methanol for 3 days at room temperature.

\begin{tabular}{|l|c|c|c|c|c|c|c|}
\hline \multicolumn{1}{|c}{} & CZ & PP1 & PP2 & PP3 & PP4 & PP5 \\
\hline Glycerin & & $<0.1$ & - & - & - & 0.2 \\
\hline Phenol, 2,4-bis(1,1-dimethylethyl)- & - & - & - & $<0.1$ & - & 0.1 \\
\hline Methyl myristate & - & 0.1 & - & - & - & - \\
\hline Methyl palmitate & - & 2.2 & $<0.1$ & - & 0.1 & 0.7 \\
\hline Methyl stearate & - & 3.6 & - & - & - & 8.5 \\
\hline Hexadecanamide & - & - & - & - & 0.5 & - \\
\hline 9-Octadecenamide & - & - & - & - & 2.4 & - \\
\hline Octadecanamide & - & - & - & - & 0.7 & - \\
\hline Glyceryl monostearate & - & - & - & - & - & 0.6 \\
\hline $\begin{array}{l}\text { Results are reported in } \mu \text { g/part; “-": Not detected. Values represent the } \\
\text { mean of duplicate samples. }\end{array}$
\end{tabular}

as mold release agents in the manufacture of plastic components. However, extracts from microcentrifuge tubes made of CZ did not differ from controls and contained no identifiable compounds (Table 2). In contrast, few compounds were extracted with DMSO from tubes made of PP and none from the one made of $\mathrm{CZ}$ under these conditions (data not shown). Several of these extracts contained dimethoxysulfone and 2,4-dithiapentane, which presumably are derived from the solvent.

Our data indicate that in a variety of physical tests, including centrifugation at high speed, freeze-thaw, protein and peptide adsorption, autoclavability, chemical resistance, and heating to $95^{\circ} \mathrm{C}$, tubes made of $\mathrm{CZ}$ performed as well as those made of PP. Tubes made of CZ were also shown to have several advantages over the tubes made of PP, such as lower permeability to moisture and gases such as oxygen (8). CZ's transparency greatly facilitates visual sample inspection, which can be a challenge with tubes made of PP because those tubes are translucent. The clarity of CZ permits easier detection of particulates, recovery of pelleted material after centrifugation, and recovery of soluble molecules from layers that have been separated by density such as in small-scale protocols for the isolation of nucleic acids from biological samples $(10,11)$.

The high purity of the CZ resin makes it suitable for use in analytical procedures where the contamination of samples by small molecules may be a concern, such as the determination of protein or nucleic acid concentration by UV spectroscopy and in leachables studies. In the latter application, storage of biologics, including biotherapeutic proteins, in vials or syringes requires identifi-

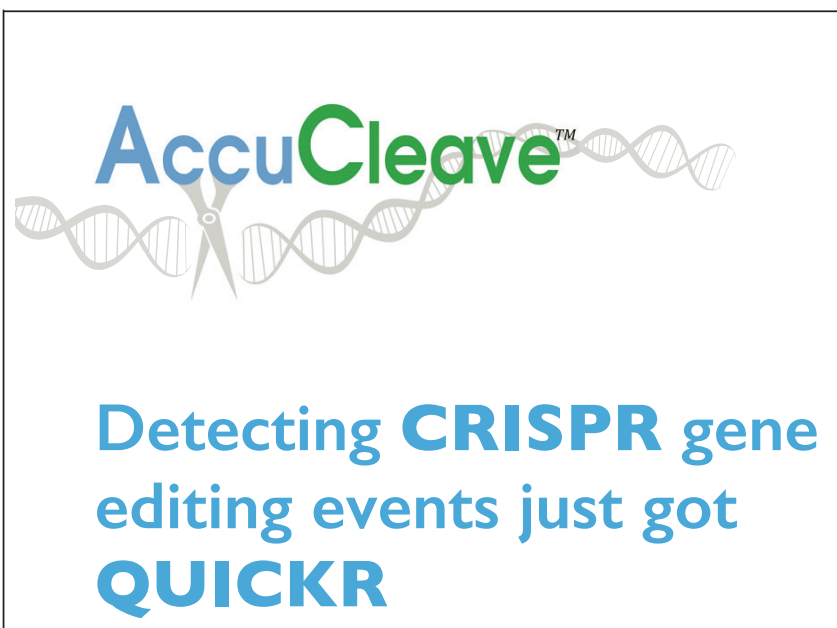

Introducing AccuCleave for use with agarose gels

- Simple and accurate enzymatic digestion assay

- Reduce sequencing costs and times with efficient screening methods

- Optimized Taq eliminates time consuming PCR cleanup

Streamline your genetic editing workflows at www.atti-us.com/AccuCleave

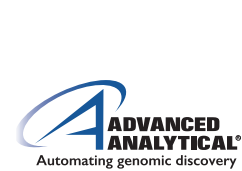




\section{Uniquely designed for when precision is paramount}

\begin{abstract}
The new Applied Biosystems ${ }^{\text {TM }}$ MicroAmp ${ }^{\text {TM }}$ 8-Tube Strip with attached optical or domed caps offers a combination of features designed to lead to a successful PCR/qPCR result every time.
\end{abstract}

- Individually attached caps

- Etched labeling on individual tubes

- Dual side tabs for strip labeling

- Graduated $20 \mu \mathrm{L}$ measuring markers

Available exclusively for Applied Biosystems $^{\text {TM }}$ thermal cyclers to provide optimal PCR results.

\section{Take control of your \\ PCR reactions at \\ thermofisher.com/ microamptubestripswithcaps}

cation of the small molecules that leach from these containers into the drug product. A protein depletion step is essential prior to analysis of these contaminants by HPLC or GC, frequently coupled with MS. Protein precipitation by addition of trichloroacetic acid or organic solvent or by heating followed by centrifugation in PP microcentrifuge tubes is frequently used to prepare these samples for analysis. However, this step may inadvertently introduce additional contaminants from the tube that interfere with interpretation of chromatograms, an issue that could be avoided or at least reduced with tubes made of $\mathrm{CZ}$.

Some manufacturers have begun to offer PP tubes that are made with fewer additives. However, the impact of such modifications on tube performance and lifespan is unclear. Improvements have also been made to reduce protein and nucleic acid adsorption. Eppendorf, for example, has introduced a line of tubes with reduced adsorption by a process that does not involve the use of a material such as silicone to coat the surface. In these tubes, a proprietary, two-component polymer mix creates a hydrophilic surface that enables optimal recovery of protein and DNA samples.

The properties of COPs, including their high purity, biocompatibility, and reduced breakability, have made them increasingly popular as an alternative to glass in the manufacture of syringes and vials, particularly for use with protein-based drugs. COPs have also been shown to be suitable for diverse laboratory applications, including microtiter plates (8) and microfluidic devices (9). Since microcentrifuge tubes made of the COP CZ have low levels of leachable substances and are metal-free, they present an attractive alternative when using enzymes and other labile biomolecules where stability may be a concern. In addition, the high optical clarity of $\mathrm{CZ}$ suggests applications, several which have been described in this study, for which tubes made of PP are inadequate. Researchers and manufacturers are likely to continue to find new uses for COPs both in medicine and in research laboratories in the future.

\section{Author contributions}

L.W. and V.V. conceived and designed the experiments. R.E. and L.W. performed the experiments and carried out data analyses. The paper was written by L.W.

\section{Acknowledgments}

We thank Ibuki Suzuki and the engineering group at Daikyo Seiko, Ltd. for providing the prototype microcentrifuge tube described in this study. This research did not receive any specific grant from funding agencies in the public, commercial, or not-for-profit sectors.

\section{Competing interests}

The authors declare no competing interests.

\section{References}

1. Lewis, L.K., M.H. Robson, Y. Vecherkina, C. Ji, and G.W. Beall. 2010. Interference with spectrophotometric analysis of nucleic acids and proteins by leaching of chemicals from plastic tubes. Biotechniques 48:297-302.

2. McDonald, G.R., A.L. Hudson, S.M.J. Dunn, H. You, G.G. Baker, R.M. Whittal, J.W. Martin, A. Jha, et al. 2008. Bioactive contaminants leach from disposable laboratory plasticware. Science 322:917.

3. Shin, J.U., J.L. Park, C. Liu, J. He, and S.C. Kim. 2005. Chemical structure and physical properties of cyclic olefin copolymers. Pure Appl. Chem. 77:801814.

4. Eakins, M.N. 2005. New plastics for old vials. Bioprocess Int. 3:52-58.

5. Vilivalam, V.D. and F.L. DeGrazio. 2010. Plastic packaging for parenteral drug delivery, p. 305-323. In S. Nema and J.D. Ludwig (Eds.), Pharmaceutical Dosage Forms: Parenteral Medications (3rd Ed., Vol.1). Informa Healthcare, New York, NY.

6. Woods, E.J., A. Bagchi, R. Nase, and V. Vilivalam. 2010. Container system for enabling commercia production of cryopreserved cell therapy products. Regen. Med. 5:659-667.

7. DeGrazio, F., J. Runkle, J. Smythe, and A. Miller. 2009. Analysis of biopharmaceutical market-appropriate plastic syringe barrel for extractables. PDA J. Pharm. Sci. Technol. 63:360-367.

8. Niles, W.D. and P. Coassin. 2008. Cyclic olefin polymers: innovative materials for high-density multiwell plates. Assay Drug Dev Technol. 6:577-590.

9. Nunes, P.S., P.D. Ohlsson, O. Ordeig, and J.P. Kutter. 2010. Cyclic olefin polymers: emerging materials for lab-on-a-chip applications. Microfluid. Nanofluidics 9:145-161.

10. Chomczynski, P. 1993. A reagent for the single-step simultaneous isolation of RNA, DNA and proteins from cell and tissue samples. BioTechniques 15:532537.

11. Chomczynski, P. and N. Sacchi. 1987. Single-step method of RNA isolation by acid-guanidinium thiocyanate-phenol-chloroform extraction. Anal. Biochem. 162:156-159.

12. Sambrook, J. and S.W. Russell. 2001. Molecular Cloning: A Laboratory Manual (3rd ed.). Cold Spring Harbor Press, Cold Spring Harbor, NY.

Received 10 August 2016; accepted 16 March 2017.

Address correspondence to Lloyd Waxman, West Pharmaceutical Services, Exton, PA 19341. E-mail: lloyd.waxman@westpharma.com

To purchase reprints of this article, contact: biotechniques@fosterprinting.com 